\title{
The high prevalence of the poor and ultrarapid metabolite alleles of CYP2D6, CYP2C9, CYP2C19, CYP3A4, and CYP3A5 in Taiwanese population
}

\author{
Ya-Huei Liou · Chien-Ting Lin · Ying-Jye Wu • \\ Lawrence Shih-Hsin Wu
}

Received: 15 May 2006/ Accepted: 18 June 2006/Published online: 19 August 2006

(C) The Japan Society of Human Genetics and Springer-Verlag 2006

\begin{abstract}
Genetic polymorphisms of drug metabolizing enzymes, such as cytochromes P450 (CYPs), play major roles in the variations of drug responsiveness in human. The aim of this study is to identify the high prevalence (minor allele frequencies $>1 \%$ ) of the abnormal metabolite alleles of CYP2C9, CYP2C19, CYP2D6, CYP3A4, and CYP3A5 in the Taiwanese population. The genotyping of the functional single nucleotide polymorphisms (SNPs) of CYPs were conducted by direct exon sequencing in 180 Taiwanese volunteers. Twenty-one unique SNPs including three newly identified SNPs were detected in the Taiwanese population. Six of the 21 SNPs in five genes showed frequencies more than $1 \%$. The results indicated that it could be very useful and important in developing an inexpensive, convenient, and precise genotyping method for the high prevalence of CYPs metabolizing abnormal alleles in the Taiwanese population.
\end{abstract}

Keywords CYP2C9 CYP2C19 CYP2D6 CYP3A4 · CYP3A5 $\cdot$ SNP $\cdot$ Taiwanese population

\section{Introduction}

Personalized medicine based on an individual's genetic make-up has been becoming a reality as the need for

Y.-H. Liou · C.-T. Lin · Y.-J. Wu · L. S.-H. Wu ( $\bowtie)$

Research and Product Development, Vita Genomics Inc., 7Fl., No.6, Sec.1, Jungshing Road, Wugu Shiang,

Taipei County 248, Taiwan

e-mail: lawrence.wu@vitagenomics.com pharmacogenomics has moved from the research setting into the clinical laboratory (Jannetto et al. 2004). However, the selection of appropriate technologies to perform personalized medicine is extremely critical, and requires careful consideration of several factors including prior knowledge of the polymorphisms, sensitivity, and specificity of the methods used, clinical sample requirements, clinical utilities, and the development cost.

Cytochrome $\mathrm{P} 450$ ( $\mathrm{P} 450)$ is responsible for most enzymatic oxidation reactions, and is often ratelimited for the fate of a drug in the body. Therefore, it is expected that dysfunction of P450 may lead to unexpected drug effects and toxicity (Nagata and Yamazoe 2002). Several key drug-metabolizing enzymes, such as P450 (CYP) 2D6, 2C9, 2C19, 3A4, and $3 \mathrm{~A} 5$, are inherited mutations (or polymorphisms) that lead to different drug responses (Weinshilboum 2003; Evans and McLeod 2003). Polymorphisms of human drug metabolism are associated with specific phenotypes and genotypes. The phenotype is distinguished by the activities or contents of an enzyme. Individuals who have normal metabolic activity are called extensive metabolizers (EM) whereas individuals with defective metabolic activity are called poor metabolizers (PM; Meyer 1990). It has been reported that phenotypes associated with genetic variations often contribute to differences in drug metabolism and the dynamics of drug-drug interactions (Solus et al. 2004).

Although pharmacogenomic intervention cannot assume to be cost-effective for all clinical practice, some key aspects of cost-effectiveness of pharmacogenomics were described (Phillips and Van Bebber 2004). One aspect previously described is the 
prevalence of a specific genetic mutation in a population because testing was no longer cost-effective for lower mutation prevalence (Eckman et al. 2002). In this study, we screened the single nucleotide polymorphism associated with enzyme activity of CYP 2D6, 2C9, 2C19, 3A4, and 3A5, and identified a high prevalence of functional polymorphism in the Taiwanese population. The study was the first comprehensive polymorphism analysis of drug-metabolizing cytochrome genes to be performed in the Taiwanese population. The data would allow us to develop an inexpensive and simple genotyping method for detecting the high prevalence of PM and ultrarapid metabolizer (UM) alleles in the Taiwanese/Asian population.

\section{Materials and methods}

DNA preparation

Genomic DNA was extracted from 180 unrelated HanChinese volunteers living in Taiwan. Clinical samples were collected with written informed consent from all the participants recruited. DNA was isolated from blood samples using QIAamp DNA Blood kit (QIAGEN, Valencia, CA, USA) according to the manufacturer's instructions. The quality of the isolated genomic DNA was checked using agarose gel electrophoresis analysis, the quantity was determined by spectrophotometer, and stored at $-80^{\circ} \mathrm{C}$ until use.

\section{SNP genotyping by sequencing}

Fragments of DNA flanking the genomic region of the selected SNPs were amplified by ABI 9700 thermal cycler using two pairs of forward and reverse primers. The information regarding primers and genotyped SNPs is listed in Table 1. The fragments of polymer chain reaction (PCR) products were sequenced by an ABI 3700 automatic sequencer according the manufacturer's protocol (Applied Biosystems, Foster City, CA, USA). The sequence data were analyzed using PolyPhred software to identify the potential candidate SNPs. The potential SNPs were manually checked to ensure the presence of a true SNP and the allele of each individual. Three independent manual confirmations were performed for all the sequence data and only those data that were confirmed were subjected to the subsequent statistical analysis. The identified SNPs and related primers are listed in Table 1.

\section{Results}

Six SNPs associated with the PM/UM phenotype had a high prevalence in the Taiwanese population

We investigated the frequencies of five $\mathrm{P} 450$ genes of $\mathrm{PM} / \mathrm{UM}$-associated alleles in 180 Han-Chinese volunteers in Taiwan. As Table 1 showed, 21 SNPs were detected by our screening in the Taiwanese population. Three SNPs, VGV 3030 in CYP2C19 exon 1, VGV1995 in CYP3A4 exon 11, and VGV2643 in CYP2D6 intron 5, were the newly identified SNPs in the current study. Six of the 21 SNPs in five genes associated with PM/UM phenotypes showed a frequency of more than $1 \%$ (Table 1). Compared with other ethnic populations, the allele frequencies of six SNPs associated with PM/UM in the Taiwanese population are similar to those of other Asian populations (Chinese-Asian, Japanese, Korean), but different from the Caucasian and African-American populations (Table 2). In Table 2, the total numbers of participants analyzed are less than 180 for some genes because those participants with missing genotyping or an ambiguous genotype calling were not analyzed.

High prevalence PM/UM genotype frequencies in the Taiwanese population

The high prevalence (frequencies more than 1\%) of genotypes associated with abnormal metabolic rates are listed in Table 3. We did not find the homozygous CYP2C9*3 and CYP2D6*5 alleles in this study. We detected several participants who were heterozygous with both CYP2C19*2 and $* 3$ loci. Nevertheless, we could not determine whether or not these two inactive alleles are on the same chromosome or on a different one. The participants who were heterozygous with both CYP2C19*2 and *3 loci should be defined as PM according to the haplotype analysis in the Japanese population because CYP2C19*2 and *3 were suggested to exist exclusively on the same chromosome in this previous report (Fukushima-Uesaka et al. 2005). In general, the PM, IM (intermediate metabolizer), EM and UM phenotypic categories correspond to two inactive alleles, one inactive allele, two normal active alleles, and two over-active alleles respectively. Because the CYP2D6*10 allele reduces, but does not abolish enzyme activity, being homozygous with CYP2D6*10 therefore represents the IM phenotype. 


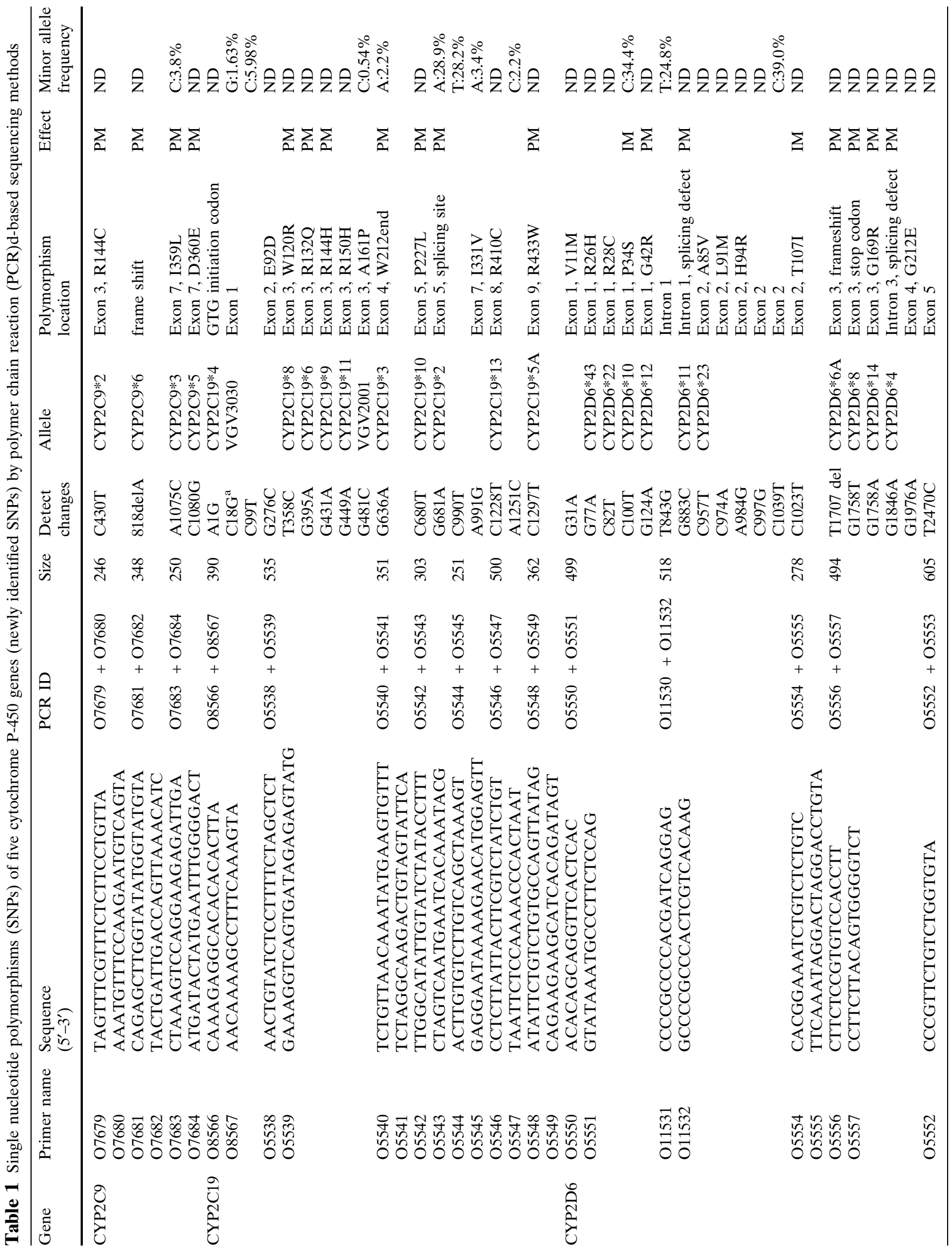




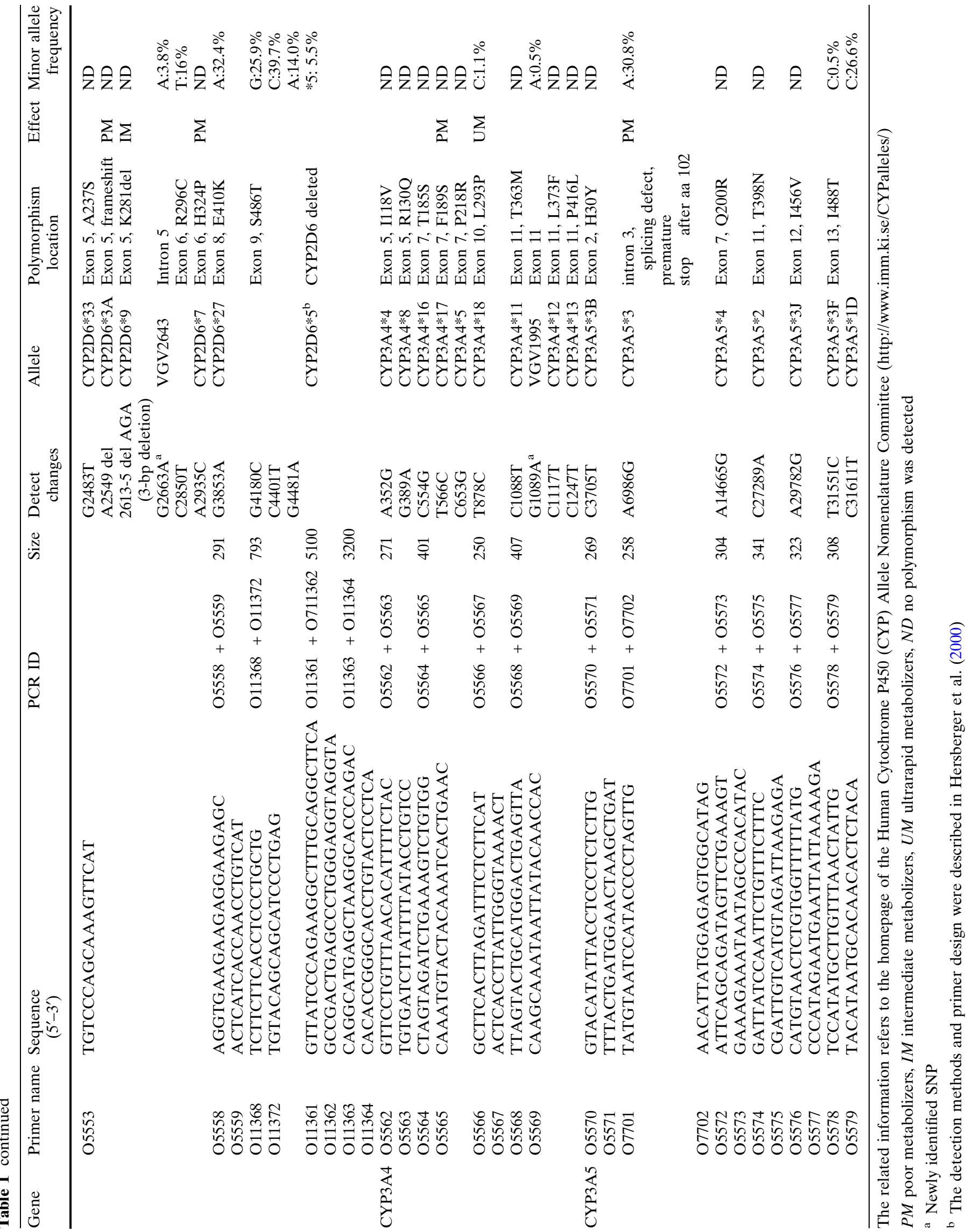




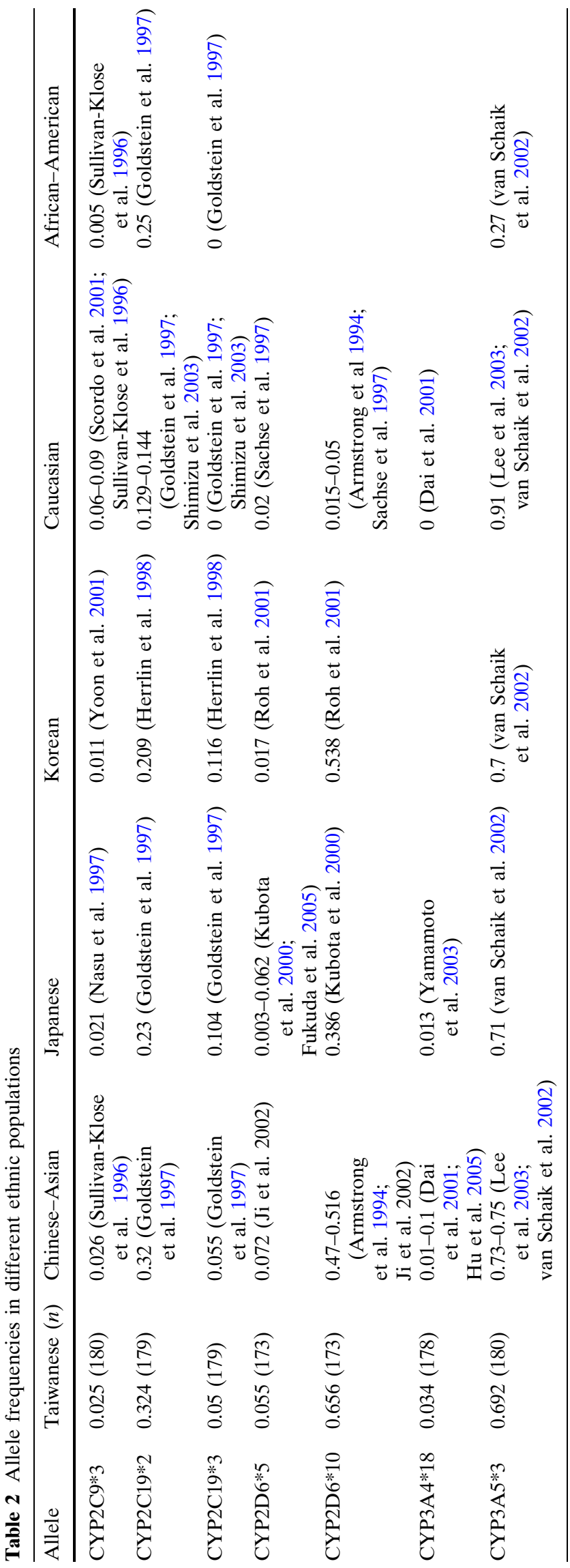

Table 3 Genotype frequencies of six SNPs identified in the present study

\begin{tabular}{|c|c|c|c|c|}
\hline Gene & Genotype & $\begin{array}{l}\text { Number of } \\
\text { individuals }\end{array}$ & Frequency & $\begin{array}{l}\text { Phenotype } \\
\text { interpretation }\end{array}$ \\
\hline \multirow[t]{2}{*}{ CYP2C9 } & CYP2C $9 * 1 / * 1$ & 171 & 0.950 & EM \\
\hline & CYP2C $9 * 1 / * 3$ & 9 & 0.050 & IM \\
\hline \multirow{5}{*}{$\begin{array}{r}\text { CYP2 } \\
\text { C19 }\end{array}$} & CYP2C19*1/*1 & 65 & 0.365 & EM \\
\hline & CYP2C19*1/*2 & 80 & 0.449 & IM \\
\hline & CYP2C19*1/*3 & 12 & 0.067 & IM \\
\hline & CYP2C19*2/*2 & 15 & 0.084 & PM \\
\hline & CYP2C19*2/*3 & 6 & 0.034 & PM \\
\hline \multirow[t]{5}{*}{ CYP2D6 } & CYP2D6*1/*1 & 24 & 0.139 & EM \\
\hline & CYP2D6*1/*5 & 7 & 0.040 & IM \\
\hline & CYP2D6*1/*10 & 45 & 0.260 & EM \\
\hline & CYP2D $6 * 5 / * 10$ & 12 & 0.069 & $\mathrm{IM}$ \\
\hline & CYP2D6*10/*10 & 85 & 0.491 & IM \\
\hline \multirow[t]{3}{*}{ CYP3A4 } & CYP3A4*1/*1 & 168 & 0.944 & EM \\
\hline & CYP $3 A 4 * 1 / * 18$ & 8 & 0.045 & EM \\
\hline & CYP3A $4 * 18 / * 18$ & 2 & 0.011 & UM \\
\hline \multirow[t]{3}{*}{ CYP3A5 } & CYP3A5*1/*1 & 16 & 0.089 & EM \\
\hline & CYP3A5* $1 / * 3$ & 79 & 0.439 & $\mathrm{IM}$ \\
\hline & CYP $3 A 5 * 3 / * 3$ & 85 & 0.472 & PM \\
\hline
\end{tabular}

$E M$ extensive metabolizers

\section{Discussion}

The likely response of an individual to a drug, such as the risk of a toxic event, is thus a complex equation involving multiple variables. However, inherited unique genetic polymorphisms (usually inactivating) are one of the major causes of variations in drug responsiveness (Evans and Johnson et al. 2001). It has been reported that the drug dosages used in clinical trials with east Asian participants are typically lower than those used in trials with western participants (Yu et al. 1996; Ross et al. 2001). Selecting polymorphisms with high frequencies of drug-metabolizing enzymes in different populations is a necessary and critical task. Therefore, an easy-to-use tool urgently needs to be developed by integrating the population's specific DME polymorphisms for clinical practice in the near future.

CYP2D6*5 represents deletion of the CYP2D6 gene and its frequency is larger than $1 \%$ in the Taiwanese population. Theoretically, the genotype frequency of homozygous CYP2D6*5 is about $0.3 \%\left(0.055^{2}\right)$ and represents the PM phenotype. However, we could not find homozygous CYP2D6*5 in this study. Similarly, CYP2D6*10 is another high frequency allele representing the IM phenotype in this study population. Most Taiwanese are homozygous CYP2D6*10 and belong to the IM phenotype. Both transheterozygous CYP2D6*5/*10 and homozygous CYP2D6*10/*10 represent the IM phenotype. Because of this, in the Taiwanese population it is likely that the IM 
transheterozygous genotyping with CYP2D6*5/*10 could be wrongly genotyped as CYP2D6*10/*10 due to having the same IM classification.

The CYP2C19*1/*2 and $* 1 / * 3$ with the IM classification accounted for about $52 \%(0.449+0.067)$ of CYP2C19 genotypes. Over $50 \%$ of CYP2D6 genotyped individuals were related to the IM phenotype. The abnormal metabolic genotypes of the major drugmetabolizing cytochromes CYP2C9, CYP2C19, and CYP2D6, are usually linked to the IM phenotype. These observations may provide some indication as to why the drug dosages used in clinical trials with east Asian participants are usually lower than those used in trials with western participants.

The genotype of homozygous CYP3A5*3 is classified as PM and occurred in $47.2 \%$ Taiwanese. Previous studies on CYP3A5 in vitro and in humans have provided inconsistent information on whether CYP3A5 plays a significant role in the metabolism of CYP3A substrates in vivo (Williams et al. 2003). Further clarification is required to differentiate the relative contributions of CYP3A4 and CYP3A5 in vivo.

Acknowledgements We thank Dr. Jui-Lin Chen for providing valuable suggestions for SNP selection. We also thank Ms. Peiwen Wang and Ms. Medge Liao for technical assistance.

\section{References}

Armstrong M, Fairbrother K, Idle JR, Daly AK (1994) The cytochrome P450 CYP2D6 allelic variant CYP2D6J and related polymorphisms in a European population. Pharmacogenetics 4:73-81

Dai D, Tang J, Rose R, Hodgson E, Bienstock RJ, Mohrenweiser HW, Goldstein JA (2001) Identification of variants of CYP3A4 and characterization of their abilities to metabolize testosterone and chlorpyrifos. J Pharmacol Exp Ther 299:825-831

Eckman MH, Singh SK, Erban JK, Kao G (2002) Testing for factor $\mathrm{V}$ Leiden in patients with pulmonary or venous thromboembolism: a cost-effectiveness analysis. Med Decis Making 22:108-124

Evans WE, Johnson JA (2001) Pharmacogenomics: the inherited basis for interindividual differences in drug response. Ann Rev Genomics Hum Genet 2:9-39

Evans WE, McLeod HL (2003) Pharmacogenomics-drug disposition, drug targets, and side effects. $\mathrm{N}$ Engl J Med 348:538-549

Fukuda T, Maune H, Ikenaga Y, Naohara M, Fukuda K, Azuma J (2005) Novel structure of the CYP2D6 gene that confuses genotyping for the CYP2D6*5 allele. Drug Metab Pharmacokinet 20:345-350

Fukushima-Uesaka H, Saito Y, Maekawa K, Ozawa S, Hasegawa R, Kajio H, Kuzuya N, Yasuda K, Kawamoto M, Kamatani N, Suzuki K, Yanagawa T, Tohkin M, Sawada J (2005) Genetic variations and haplotypes of CYP2C19 in a Japanese population. Drug Metab Pharmacokinet 20:300-307
Goldstein JA, Ishizaki T, Chiba K, de Morais SM, Bell D, Krahn PM, Evans DA (1997) Frequencies of the defective CYP2C19 alleles responsible for the mephenytoin poor metabolizer phenotype in various Oriental, Caucasian, Saudi Arabian and American black populations. Pharmacogenetics 7:59-64

Herrlin K, Massele AY, Jande M, Alm C, Tybring G, Abdi YA, Wennerholm A, Johansson I, Dahl ML, Bertilsson L, Gustafsson LL (1998) Bantu Tanzanians have a decreased capacity to metabolize omeprazole and mephenytoin in relation to their CYP2C19 genotype. Clin Pharmacol Ther 64:391-401

Hersberger M, Martin-Jaun J, Rentsch K, Hansler E (2000) Rapid detection of the CYP2D6*3, CYP2D6*4, and CYP2D6*6 alleles by tetra-primer PCR and of the CYP2D6*5 allele by multiplex long PCR. Clin Chem 48:1072-1077

Hu YF, He J, Chen GL, Wang D, Liu ZQ, Zhang C, Duan LF, Zhou HH (2005) CYP3A5*3 and CYP3A4*18 single nucleotide polymorphisms in a Chinese population. Clin Chim Acta 353:187-192

Jannetto PJ, Laleli-Sahin E, Wong SH (2004) Pharmacogenomic genotyping methodologies. Clin Chem Lab Med 42:12561264

Ji L, Pan S, Wu J, Marti-Jaun J, Hersberger M (2002) Genetic polymorphisms of CYP2D6 in Chinese mainland. Chin Med J (Engl) 115:1780-1784

Kubota T, Yamaura Y, Ohkawa N, Hara H, Chiba K (2000) Frequencies of CYP2D6 mutant alleles in a normal Japanese population and metabolic activity of dextromethorphan $O$-demethylation in different CYP2D6 genotypes. Br J Clin Pharmacol 50:31-34

Lee SJ, Usmani KA, Chanas B, Ghanayem B, Xi T, Hodgson E, Mohrenweiser HW, Goldstein JA (2003) Genetic findings and functional studies of human CYP3A5 single nucleotide polymorphisms in different ethnic groups. Pharmacogenetics 13:461-472

Meyer UA (1990) Genetic polymorphisms of drug metabolism. Fundam Clin Pharmacol 4:595-615

Nagata K, Yamazoe Y (2002) Genetic polymorphism of human cytochrome P450 involved in drug metabolism. Drug Metabol Pharmacokinet 17:167-189

Nasu K, Kubota T, Ishizaki T (1997) Genetic analysis of CYP2C9 polymorphism in a Japanese population. Pharmacogenetics 7:405-409

Phillips KA, Van Bebber SL (2004) A systematic review of costeffectiveness analyses of pharmacogenomic interventions. Pharmacogenomics 5:1139-1149

Roh HK, Chung JY, Oh DY, Park CS, Svensson JO, Dahl ML, Bertilsson L (2001) Plasma concentrations of haloperidol are related to CYP2D6 genotype at low, but not high doses of haloperidol in Korean schizophrenic patients. Br J Clin Pharmacol 52:265-271

Ross AM, Gao R, Coyne KS, Chen J, Yao K, Yang Y, Qin X, Qian S, Yao M, TUCC Investigators (2001) A randomized trial confirming the efficacy of reduced dose recombinant tissue plasminogen activator in a Chinese myocardial infarction population and demonstrating superiority to usual dose urokinase: the TUCC trial. Am Heart J 142:244-247

Sachse C, Brockmoller J, Bauer S, Roots I (1997) Cytochrome P450 2D6 variants in a Caucasian population: allele frequencies and phenotypic consequences. Am J Hum Genet 60:284-295 
Scordo MG, Aklillu E, Yasar U, Dahl ML, Spina E, IngelmanSundberg M (2001) Genetic polymorphism of cytochrome $\mathrm{P} 4502 \mathrm{C} 9$ in a Caucasian and a black African population. $\mathrm{Br}$ J Clin Pharmacol 52:447-450

Shimizu T, Ochiai H, Asell F, Shimizu H, Saitoh R, Hama Y, Katada J, Hashimoto M, Matsui H, Taki K, Kaminuma T, Yamamoto M, Aida Y, Ohashi A, Ozawa N (2003) Bioinformatics research on inter-racial difference in drug metabolism. I. Analysis on frequencies of mutant alleles and poor metabolizers on CYP2D6 and CYP2C19. Drug Metab Pharmacokinet 18:48-70

Solus JF, Arietta BJ, Harris JR, Sexton DP, Steward JQ, McMunn C, Ihrie P, Mehall JM, Edwards TL, Dawson EP (2004) Genetic variation in eleven phase I drug metabolism genes in an ethnically diverse population. Pharmacogenomics 5:895-931

Sullivan-Klose TH, Ghanayem BI, Bell DA, Zhang ZY, Kaminsky LS, Shenfield GM, Miners JO, Birkett DJ, Goldstein JA (1996) The role of the CYP2C9-Leu359 allelic variant in the tolbutamide polymorphism. Pharmacogenetics 6:341-349
Van Schaik RH, van der Heiden IP, van den Anker JN, Lindemans J (2002) CYP3A5 variant allele frequencies in Dutch Caucasians. Clin Chem 48:1668-1671

Weinshilboum R (2003) Inheritance and drug response. N Engl J Med 348: 529-537

Williams JA, Cook J, Hurst SI (2003) A significant drugmetabolizing role for CYP3A5? Drug Metab Dispos 31:1526-1531

Yamamoto T, Nagafuchi N, Ozeki T, Kubota T, Ishikawa H, Ogawa S, Yamada Y, Hirai H, Iga T (2003) CYP3A4(*)18: it is not rare allele in Japanese population. Drug Metab Pharmacokinet 18:267-268

Yoon YR, Shon JH, Kim MK, Lim YC, Lee HR, Park JY, Cha IJ, Shin JG (2001) Frequency of cytochrome P450 2C9 mutant alleles in a Korean population. Br J Clin Pharmacol 51:277-280

Yu HC, Chan TY, Critchley JA, Woo KS (1996) Factors determining the maintenance dose of warfarin in Chinese patients. QJM 89:127-135 